\title{
Knowledge, Attitude and Perceptions of Indian long-distance Train Travellers Towards Medicinal Drugs, Healthcare, and Hygiene while Travelling: A Questionnaire-based Survey
}

\author{
Pranjit Santonu Bhajoni, Girish Gulab Meshram*
}

\section{Pranjit Santonu}

Bhajoni, Girish Gulab Meshram*

Department of Pharmacology, Postgraduate Institute of Medical Education and Research and Dr. Ram Manohar Lohia Hospital, New Delhi 110001, INDIA.

\section{Correspondence}

Dr. Girish Gulab Meshram M.D.

Assistant Professor, Department of Pharmacology, Postgraduate Institute of Medical Education and Research and Dr. Ram Manohar Lohia Hospital, New Delhi 110001, INDIA

Mobile no: +918376010560

Email: drgirish23@yahoo.co.in

History

- Submission Date: 31-08-16

- Revised Date: 23-03-17

- Accepted Date: 11-04-17

DOI : 10.5530/ijmedph.2017.2.17

Article Available online

http://www.ijmedph.org/v7/i2

Copyright

(C) 2017 Phcog.Net. This is an openaccess article distributed under the terms of the Creative Commons Attribution 4.0 International license.

\begin{abstract}
Background: Although a large population uses the Indian Railways for long-distance journeys, data about their knowledge, attitude, and perception towards medicinal drugs, healthcare, and hygiene while travelling, is sparse. Methods: We conducted a cross-sectional survey from March 2016 to December 2016 among 114 randomly sampled long-distance train passengers. A self-administered questionnaire, directed towards knowledge, attitude, and perception of passengers towards medicinal drugs, healthcare, and hygiene while travelling, was administered. The completeness of the questionnaire was validated by an interview. The association between the type of coach and the various variables mentioned in the questionnaire was calculated by the chi-square test or the Fisher's exact test. Results: Of the 114 respondents (77.19 \% males, $22.81 \%$ females), $61.4 \%$ carried medicines with them while travelling. The most common class of drug carried by the respondents was non-steroidal anti-inflammatory drugs (NSAIDs). Although $61.4 \%$ of the participants claimed to consult a doctor before consuming any drug, $43.85 \%$ of them had no knowledge of either the indications or the adverse effects of the drugs that they consumed. $32.45 \%$ of the respondents complained of being physically/psychologically stressed during/after the journey. A majority of the travellers (93.85 $\%$ ) believed that hygiene and cleanliness had a role in preventing illness while travelling. Only $2.69 \%$ of the respondents were aware of the healthcare facilities provided by the Indian Railways. A significant $(p<0.05$ ) association was found between the type of coach and the method of obtaining drug information, feeling stressed, and food preference. However, due to the small sample size these findings cannot be generalized. Conclusion: There is a need to create awareness about common over-the-counter drugs among long-distance train travellers in India. Healthcare facilities provided by the Indian Railways must be publicized.
\end{abstract}

Key words: Attitude, Drugs, Healthcare, Knowledge, Long-Distance Train Travel, Perceptions.

\section{INTRODUCTION}

The railway network in India is the one of the world's largest. ${ }^{1}$ More than 13 million passengers use the Indian Railways every day. ${ }^{2}$ A total of 8224 million passengers used the Indian Railways and covered more than 1147190 million passenger $\mathrm{km}$ in the year 201415. ${ }^{3}$ The trend of passengers using railways in India, as a mode of transportation for long distances, is increasing rapidly in the past few years. ${ }^{3}$

Long-distance travelling in trains predisposes passengers to several medical conditions. First, transmission of several infectious diseases is common in closed settings such as in trains. ${ }^{4}$ Second, food and water consumed while travelling could expose passengers to gastrointestinal diseases. ${ }^{5}$ Third, longdistance travel is associated with a group of transient negative effects, collectively referred to as 'travel fatigue. ${ }^{6}$ Fourth, travelling in trains for several hours may lead to immobility and predispose travellers to deep vein thrombosis. ${ }^{7,8}$ Fifth, several pre-existing

cardiovascular, respiratory diseases could exacerbate due to the strain involved during long-distance travel. ${ }^{8}$ Since drugs play a major role in alleviating the signs and symptoms of most of the medical conditions that passengers encounter during their train journeys, inadequate knowledge about them could decrease their preparedness before a journey, decrease their ability to counter anticipated travel-related illnesses, and decrease reporting of adverse drug events. Also, following poor personal hygiene could increase the transmission rate of common gastrointestinal and respiratory diseases. Lack of information about the healthcare facilities provided by the Indian Railways could affect their attitude of seeking help in case of emergencies.

Despite the large number of passengers using the Indian Railways, data about their knowledge, attitude, and perception towards medicinal drugs, healthcare, and hygiene while travelling, is sparsely documented. Hence, the aim of the study, conducted between

Cite this article : Bhajoni PS, Meshram GG. Knowledge, attitude, and perceptions of Indian long-distance train travellers towards medicinal drugs, healthcare, and hygiene while travelling: A questionnaire-based survey. Int J Med. Public Health. 2017; 7(2):83-91. 
March 2015 to December 2015 and recruiting 114 participants, was to obtain a preliminary understanding of the knowledge, attitude, and perceptions of Indian long-distance train travellers about medicinal drugs, healthcare, and hygiene while travelling, through a questionnaire-based survey, which could provide further insight in planning and developing strategies for local health education purposes.

\section{MATERIALS AND METHODS}

The questionnaire-based survey was conducted between March 2015 and December 2015. The study was approved by the Institutional Ethical Committee of Postgraduate Institute of Medical Education and Research and Dr. Ram Manohar Lohia Hospital. The study was conducted in accordance with the International Ethical Guidelines, and the Declaration of Helsinki, as revised in 2013.

The North-East Express was selected as the suitable train for conducting the study as it comprised of mixture of both $\mathrm{AC}$ and non-AC coaches (total passenger-coaches were 22 in number), and it covered a distance of $1880 \mathrm{~km}$ in approximately $34 \mathrm{~h}$ with 2210 passengers.

The study population included Indian passengers of more than 18 years in age, travelling $\geq 1000 \mathrm{~km}$ in a long-distance train, and able to fully understand the language of the questionnaire. These criteria were checked by the investigator. Passengers who did not meet these criteria were not included in the study or their responses were excluded from the final analyses.

In order to calculate the sample size for the study, prevalence of knowledge about medicinal drugs, healthcare, and hygiene among long distance railways passengers was not available from published literature. Therefore the proportion of $46.5 \%$ (population size of long-distance train travellers was assumed to be 3719 million as per the Indian Railways database of 2014-15) 3 was considered for calculation. The confidence level was set as $95 \%$ and the acceptable margin of error was set as $10 \%$. Using Epi Info Version 7.2 (Centres for disease control and prevention, GA, USA) the sample size was calculated to be 94 , using the following formula.

Sample size $=\underline{Z}^{\underline{2}} \underline{\underline{X}(p) \times(1-p)}$

$$
c^{2}
$$

$\mathrm{Z}$ is the $\mathrm{z}$ value i.e. 1.96 for $95 \%$ confidence level, $\mathrm{p}$ is the prevalence/ proportion of the event of interest (expressed as a decimal), and $\mathrm{c}$ is the confidence interval/ margin of error (expressed as a decimal).

A self-administered, anonymous questionnaire was distributed to the passengers included in the study after obtaining their verbal consent by the investigator. The language of the questionnaire was English. The investigator travelled with the passengers in the same train. Passengers travelling in both air-conditioned (AC) and sleeper coaches participated voluntarily without any incentives. The questionnaire was split into two parts. The first part of the questionnaire included six questions about the demographic details of the passengers [Table 1]. The second part of the questionnaire comprised of 25 questions. The first 12 questions dealt with the knowledge, attitude, and perceptions of passengers towards medicinal drugs [Table 2]. The next three questions focussed on obtaining information about the various medical conditions which passengers encounter while travelling in long-distance trains and how they manage them [Table 3]. The next ten questions dealt with the knowledge, attitude, and perceptions of passengers towards hygiene while travelling in long-distance trains [Table 4]. The respondents were then interviewed to understand their current knowledge about the healthcare facilities provided by the Indian Railways to passengers on long-distance trains and their suggestions to improve the same. The details about the pre-existing acute/chronic health conditions that they suffered from and the medications that they carried were also discussed during the interview. While collecting the questionnaire back from the participants the investigator checked the completeness of the responses, and answered relevant queries if necessary.

The data of the completed questionnaire was evaluated using SPSS 21 (IBM Corporation, NY, USA). A chi-square test of independence or a Fisher's exact test was performed to examine the relation between the type of coach i.e. AC or Sleeper and the various variables in the questionnaire. $P<0.05$ was considered statistically significant.

\section{RESULTS}

The investigator approached 276 passengers of which $76(27.54 \%)$ declined to provide verbal consent for the study. The reasons for declining verbal consent were a lack of interest, language barrier, and the lengthiness of the questionnaire. Of the 200 questionnaires distributed, 148 (74 $\%)$ were received back by the investigator. The investigator could not retrieve $52(26 \%)$ of the distributed questionnaires as some of the respondents had lost the questionnaires in transit or were unwilling to complete the questionnaire. Of the 148 questionnaires received, 34 (22.97\%) respondents did not fulfil the inclusion criteria and were excluded from the final analyses. The demographic characteristics of the respondents included/excluded at each stage of the study are mentioned in Figure 1.

Demographic parameters of the 114 participants included in the final analyses are mentioned in Table 1 . A large chunk of the respondents were males $(77.19 \%)$. The majority of the respondents belonged to the young age group (50\%), followed by the middle age group (25.44\%), and then followed by the old age group (24.56\%). A majority of the participants

\section{Table 1: Demographic parameters of participants included in the final analyses.}

\begin{tabular}{|c|c|c|c|}
\hline No. & Parameters & Number (n) & Percentage \\
\hline \multirow[t]{3}{*}{1} & \multicolumn{3}{|c|}{ Gender } \\
\hline & Male & 88 & 77.19 \\
\hline & Female & 26 & 22.81 \\
\hline \multirow[t]{4}{*}{2} & Age & & \\
\hline & $18-35$ years & 57 & 50 \\
\hline & $36-55$ years & 29 & 25.44 \\
\hline & 56 and above & 28 & 24.56 \\
\hline \multirow[t]{5}{*}{3} & \multicolumn{3}{|c|}{ Frequency of long-distance train travel } \\
\hline & Once a week & 2 & 1.75 \\
\hline & Once a month & 28 & 24.56 \\
\hline & Once a year & 34 & 29.82 \\
\hline & Others & 50 & 43.86 \\
\hline \multirow[t]{3}{*}{4} & \multicolumn{3}{|c|}{ Planned or Unplanned (Tatkal) journey } \\
\hline & Planned & & 77.19 \\
\hline & Unplanned & & 22.81 \\
\hline \multirow[t]{3}{*}{5} & \multicolumn{3}{|c|}{ Travelling for medical reason } \\
\hline & Yes & 7 & 6.14 \\
\hline & No & 107 & 93.86 \\
\hline \multirow[t]{3}{*}{6} & \multicolumn{3}{|c|}{ Suffering from a chronic condition } \\
\hline & Yes & 34 & 29.82 \\
\hline & No & 80 & 70.17 \\
\hline \multirow[t]{3}{*}{7} & \multicolumn{3}{|c|}{ Type of coach } \\
\hline & Air-conditioned & 62 & 54.39 \\
\hline & Sleeper & 52 & 45.61 \\
\hline
\end{tabular}




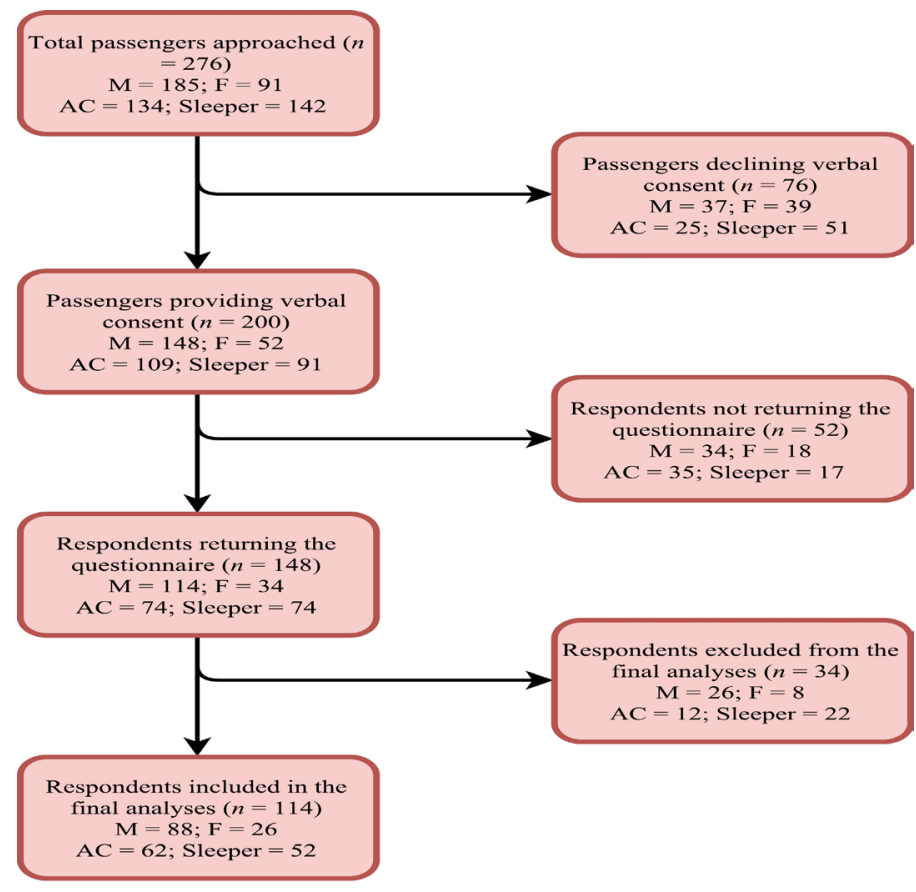

Figure 1: Flowchart depicting the demographic parameters of passengers included/excluded at each stage of the study according to their gender and type of coach.

planned their journeys in advance $(77.19 \%)$ and had variable travelling frequencies. A very few of the participants $(6.14 \%)$ were in transit for medical reasons despite the fact that $29.82 \%$ of them were suffering from a chronic health condition (Table 1$)$.

$34.21 \%$ of the participants usually carried medicines along with them during their day-to-day life, of which $88.11 \%$ suffered from a chronic illness. 70 participants $(61.40 \%)$ were carrying medicines with them while travelling in the train. Of these 70 participants, 36 participants $(51.43$ $\%)$ were suffering from a chronic/acute medical illness. The common pre-existing medical ailments that these 36 participants were suffering from were hypertension, diabetes, hypercholesterolemia, and thyroid disorders. The medications carried by them to specifically counter these disorders are enumerated in Table 5, the details of which were obtained from them during the interview. The common drugs carried by this group of travellers were antihypertensives, lipid-lowering agents, and antidiabetics. 28 participants $(77.78 \%)$ of these 36 participants correctly described the indications of all of the drugs that they carried to treat their pre-existing acute/chronic medical condition, while only 4 (11.11 $\%)$ enumerated the adverse effects (Table 5). Also, 17 (47.22 \%) of these 36 participants were carrying drugs to counter medical ailments that they probably might encounter during the train journey, in addition to the drugs that they were carrying for treating their pre-existing illness. These drugs are enlisted in Table 6. The most common class of drugs consumed in this group of passengers was NSAIDs. Of these 17 participants, 14 participants $(82.35 \%)$ accurately described the indications of the agents that they carried, while only one participant (5.88 \%) knew about the adverse effects (Table 6).

The rest of the 34 participants (48.57\%), of the 70 participants carrying medicines, were healthy participants carrying drugs to counter anticipated ailments during the journey. The drugs carried by this group of participants are enumerated in Table 7. The most common class of drugs carried by them was NSAIDs. 20 (58.82\%) of these 34 participants enlisted the correct indications of the drugs that they carried, while only 3 participants (8.23\%) enumerated the adverse effects (Table 7). 44 par- ticipants were travelling without any medicines and had no history of suffering from any acute/chronic ailment.

$31.58 \%$ of the participants said that the medicines that they carried were to treat a chronic health condition (Table 2). Almost half of the respondents did not carry medicines while they were travelling via another mode of transportation. Although, most of the respondents (61.4 $\%)$ claimed to consult a doctor before consuming any medicinal drug, $40.35 \%$ of them agreed to have consumed drugs in the past without any professional consultation. Most of the respondents ( $43.85 \%$ ) said to have no knowledge of either the indications or the adverse effects of the drugs that they consume. $87.72 \%$ of the participants did not understand the term 'over-the-counter (OTC) medicines', while $54.39 \%$ of them did not know the difference between generic and branded drugs. $40.38 \%$ of the of the respondents, who claimed to know the difference between generic and brand names, thought that branded drugs were cheaper than generic drugs. $40.35 \%$ of the respondents consumed herbal medications. A majority of the respondents $(84.21 \%)$ did not have faith in the knowledge of pharmacists about the drugs at pharmacies located at railway stations and did not prefer to buy medications from them (Table 2).

$32.46 \%$ of the respondents found themselves to be stressed physically or psychologically during/after a long-distance train journey. The most common medical condition that the participants complained of during/ after a train journey was fatigue followed by headache (Table 2). A fraction of the participants $(24.56 \%)$ would not seek any treatment if they fell ill during a train journey.

A majority of the respondents preferred bottled water $(75.44 \%)$ and pantry-food (52.63\%) while travelling in long-distance trains. Most of the respondents $(73.68 \%)$ claimed to not fall ill after consuming pantry-food. $93.86 \%$ of the respondents believed that cleanliness and hygiene played an important role in preventing diseases and illnesses, while $90.35 \%$ of them believed that the process of cleanliness starts from the self. Majority of the respondents used the right hand for eating food $(83.33 \%)$, the left hand for wiping their rectum after bowel evacuation $(50.88 \%)$, and the right hand to close the tap water after using the toilet $(81.58 \%)$.

During the interview it was found that a majority of the participants $(97.31 \%)$ were unaware that there is a first-aid kit available in the train in case of an emergency. Only one respondent knew that there is a doctor on call at main train junctions. The main themes suggested by the respondents to improve the healthcare facilities in long-distance trains were recruitment of a doctor in long-distance trains, improvement in the hygiene of food/water, and cleanliness of toilets.

A significant $(P<0.05)$ relationship was found between the type of coach and the method of seeking drug information (Table 2). Also, we observed passengers travelling in an AC coach were more likely to feel stressed than were passengers in a sleeper coach $(P<0.05)$ (Table 3$)$. Also, the relationship between the food preference and the type of coach was significant $(P<0.05)$ (Table 4$)$.

\section{DISCUSSION}

The results of the study indicated that the knowledge about drugs amongst passengers travelling in long-distance trains was not satisfactory, despite a substantial number of them had long-standing ailments, carried medicines with them while travelling, and suffered from physical or psychological stress during the travel. Most respondents followed some hygienic practises while travelling and indicated a willingness to improve the cleanliness of the railways. A vast majority of the respondents had no information about the healthcare facilities provided by the Indian Railways to its passengers in long-distance trains. 
Table 2: Part of the questionnaire to assess the knowledge, attitude, and perceptions of passengers towards medicinal drugs.

\begin{tabular}{|c|c|c|c|c|c|}
\hline No. & Questions & $A C(n)$ & Sleeper ( $n)$ & P value & Total (n) \\
\hline \multirow[t]{3}{*}{1} & Do you generally carry medicines with you? & & & & \\
\hline & a) Yes & $21(33.87)$ & $18(34.62)$ & $>0.05^{*}$ & $39(34.21)$ \\
\hline & b) No & $41(66.13)$ & $34(65.38)$ & & $75(65.79)$ \\
\hline \multirow[t]{3}{*}{2} & Do you carry medicines with you while you are travelling in a train? & & & & \\
\hline & a) Yes & $43(69.35)$ & $27(51.92)$ & $>0.05^{*}$ & $70(61.40)$ \\
\hline & b) No & $19(30.65)$ & $25(48.08)$ & & $44(38.60)$ \\
\hline
\end{tabular}

2.1 If yes, are these medicines for a chronic health condition or specifically for the travel?
a) Chronic health condition

b) Travel purpose

$\begin{array}{lcll}21 & 15 & >0.05^{*} & 36(31.58) \\ 31 & 20 & & 51(44.4) \\ & & & \text { Table 5 } \\ & & & \\ (51.61) & 26(50.00) & >0.05^{*} & 58(50.88) \\ (48.39) & 26(50.00) & & 56(49.12)\end{array}$

5 Do you generally seek medical advice from:
a) Doctor
b) Non-doctor (Nurse, pharmacist, paramedic)
c) Both doctor and non-doctor

$46(74.19)$

$\begin{array}{lll}24(46.15) & <0.05^{*} & 70(61.40) \\ 10(19.23) & & 14(12.28) \\ 18(34.62) & & 30(26.32)\end{array}$

6 Have you ever consumed medicines without consulting a medical professional?
a) Yes
b) No that you consume usually?
a) Know indications only
b) Know adverse effects only
c) Know both
d) Know nothing of some

$4(6.45)$

$12(19.35)$

$18(34.62)$

$30(26.32)$

$22(35.48)$

$24(46.15)$

$>0.05^{*}$

$46(40.35)$

$40(64.51)$

$28(53.85)$

$68(59.65)$

7 Do you know about the indications and the adverse effects (side effects) of the medicines

\begin{tabular}{|c|c|c|c|}
\hline $20(32.25)$ & $4(7.69)$ & $<0.05^{* *}$ & $24(21.05)$ \\
\hline $2(3.23)$ & $8(15.38)$ & & $10(8.77)$ \\
\hline $12(19.35)$ & $18(34.62)$ & & $30(26.32)$ \\
\hline $28(45.16)$ & $22(42.31)$ & & $50(43.86)$ \\
\hline $10(16.13)$ & $4(7.69)$ & $>0.05^{\star *}$ & $14(12.28)$ \\
\hline $52(83.87)$ & 48 (92.31) & & $100(87.72)$ \\
\hline $30(48.39)$ & $22(42.31)$ & $>0.05^{\star}$ & $52(45.61)$ \\
\hline $32(51.61)$ & $30(57.69)$ & & $62(54.39)$ \\
\hline $14(46.67)$ & $13(59.10)$ & $>0.05^{*}$ & $31(59.62)$ \\
\hline $16(53.33)$ & $9(40.90)$ & & $21(40.38)$ \\
\hline $24(38.71)$ & $22(42.31)$ & $>0.05^{*}$ & $46(40.35)$ \\
\hline 38 (61.29) & $30(57.69)$ & & $68(59.65)$ \\
\hline $8(12.90)$ & $10(19.23)$ & $>0.05^{\star *}$ & 18 (15.79) \\
\hline $54(87.10)$ & $42(80.77)$ & & $96(84.21)$ \\
\hline $14(22.58)$ & $4(7.69)$ & $>0.05^{\star *}$ & $18(15.79)$ \\
\hline 48 (77.42) & $48(92.31)$ & & $96(84.21)$ \\
\hline
\end{tabular}

${ }^{*}$ Chi-square test. ${ }^{* *}$ Fisher's exact test. $\mathrm{P}<0.05$ is statistically significant. AC is air-conditioned. Total is passengers in both AC and sleeper coaches. Values in parenthesis represent percentage. 
Table 3: Part of the questionnaire to assess the knowledge, attitude, and perceptions of passengers towards various medical conditions which they encounter while travelling in long-distance trains.

\begin{tabular}{|c|c|c|c|c|c|}
\hline No. & Question & $A C$ & Sleeper & $P$ value & Total \\
\hline \multirow[t]{3}{*}{13} & $\begin{array}{l}\text { Are you stressed physically or psychologically while travelling in trains for } \\
\text { long hours? }\end{array}$ & & & & \\
\hline & a) Yes & $29(46.77)$ & $8(15.38)$ & $<0.05^{*}$ & $37(32.46)$ \\
\hline & b) No & $33(53.23)$ & $44(84.62)$ & & $77(6.54)$ \\
\hline \multirow[t]{6}{*}{14} & $\begin{array}{l}\text { Which is the most common medical condition that you feel during/after } \\
\text { your train journey? }\end{array}$ & & & & \\
\hline & a) Nil & $55(88.71)$ & $34(65.38)$ & $>0.05^{* *}$ & $89(78.07)$ \\
\hline & b) Fatigue/Exhaustion/Tiredness & $10(16.13)$ & $8(15.38)$ & & $18(15.79)$ \\
\hline & c) Headache & $2(3.22)$ & $1(1.92)$ & & $3(2.63)$ \\
\hline & d) Sleepiness & $1(1.61)$ & $2(3.85)$ & & $2(1.75)$ \\
\hline & e) Cough & $0(0.00$ & $2(3.85)$ & & $2(1.75)$ \\
\hline \multirow[t]{6}{*}{15} & What do you do when you feel unwell during a long-distance train journey? & & & & \\
\hline & a) I get off the train to seek treatment & $4(6.45)$ & $0(0.00)$ & $>0.05^{\star *}$ & $4(3.51)$ \\
\hline & b) I take the medicines that I bring with me & $26(41.94)$ & $24(46.15)$ & & $50(43.86)$ \\
\hline & c) I take the help of other passengers & $4(6.45)$ & $6(11.54)$ & & $10(8.77)$ \\
\hline & d) I enquire with the train collector & $10(16.13)$ & $12(23.08)$ & & $22(19.30)$ \\
\hline & e) Do nothing and hope for the best & $18(29.03)$ & $10(19.23)$ & & $28(24.56)$ \\
\hline
\end{tabular}

* Chi-square test. ${ }^{*}$ Fisher's exact test. $\mathrm{P}<0.05$ is statistically significant. AC is air-conditioned. Total is passengers in both AC and sleeper coaches. Values in parenthesis represent percentage.

\section{Table 4: Part of the questionnaire to assess the knowledge, attitude, and perceptions of passengers towards hygiene while travelling in long-} distance trains.

16 What type of water do you drink while travelling on a train?
a) Home brought water
b) Bottled water
c) Taps of railway stations

$10(16.13)$

$50(80.66)$

$8(15.38)$

$>0.05^{* *}$

18 (15.79)

$2(3.23)$

$36(69.23)$

$86(75.44)$

$10(8.77)$

17 How do you manage your food while travelling?
a) Homemade food
b) Vendors on the platform
c) Pantry

$30(48.39)$

$18(34.62)$

$<0.05^{* *}$

$48(42.11)$

$0(0.00)$

$6(11.54)$

$6(5.26)$

$32(51.61)$

$28(53.85)$

$60(52.63)$

18 Does pantry-food make you ill by anyway?
a) Yes
$20(32.26)$
b) No
$42(67.74)$

$10(19.23)$

$>0.05^{*}$

$30(26.32)$

$42(80.77)$

$84(73.68)$

19 Do you think that cleanliness has some value in preventing diseases?
a) Yes
b) No
20 Do you think that cleanliness starts with you picking up your litter and throwing it in the dustbin?

$60(96.77)$

47 (90.38)

$>0.05^{* *}$

$107(93.86)$

$2(3.23)$

$5(9.62)$

$7(6.14)$
a) Yes
$58(93.56)$
b) No
4 (6.45)

$44(84.62)$

$>0.05^{* *}$

$103(90.35)$

21 Do you think it is safer to drink water from the cup of your hands or directly from the bottle?
a) Cup of hand
$10(16.13)$
$10(19.23)$
$>0.05^{*}$
21 (18.42)
b) Directly from bottle
$52(83.87)$
$42(80.77)$
$93(81.58)$

22 Do you bring your own cutlery/utensils while travelling in longdistance trains?

a) Yes

$20(32.26)$

$16(30.77)$

$>0.05^{*}$

$36(31.58)$ 
b) No

23

Which hand do you use for eating your food?
a) Right
b) Left
$50(80.65)$
$45(86.54)$
$>0.05^{*}$
$95(83.33)$
$12(19.35)$
7 (13.46)
$19(16.67)$

$42(67.74)$

$36(69.23)$

$78(68.42)$

24 Which hand do you use for wiping after bowel evacuation?
a) Right
$26(48.94)$
$30(57.69)$
$>0.05^{*}$
$56(49.12)$
b) Left
$36(58.06)$
$22(42.31)$
$58(50.88)$

25 Which hand do you use for opening/closing the water tap during and just after bowel evacuation?
a) Right
$48(77.42)$
$44(84.62)$
$>0.05^{*}$
$93(81.58)$
b) Left
$14(22.58)$
$8(15.38)$
$21(18.42)$

${ }^{*}$ Chi-square test. ${ }^{*}$ Fisher's exact test. $\mathrm{P}<0.05$ is statistically significant. AC is air-conditioned. Total is passengers in both AC and sleeper coaches. Values in parenthesis represent percentage.

Table 5: Drugs carried by participants for countering pre-existing medical conditions (acute/chronic) $(\mathbf{n}=\mathbf{3 6})$.

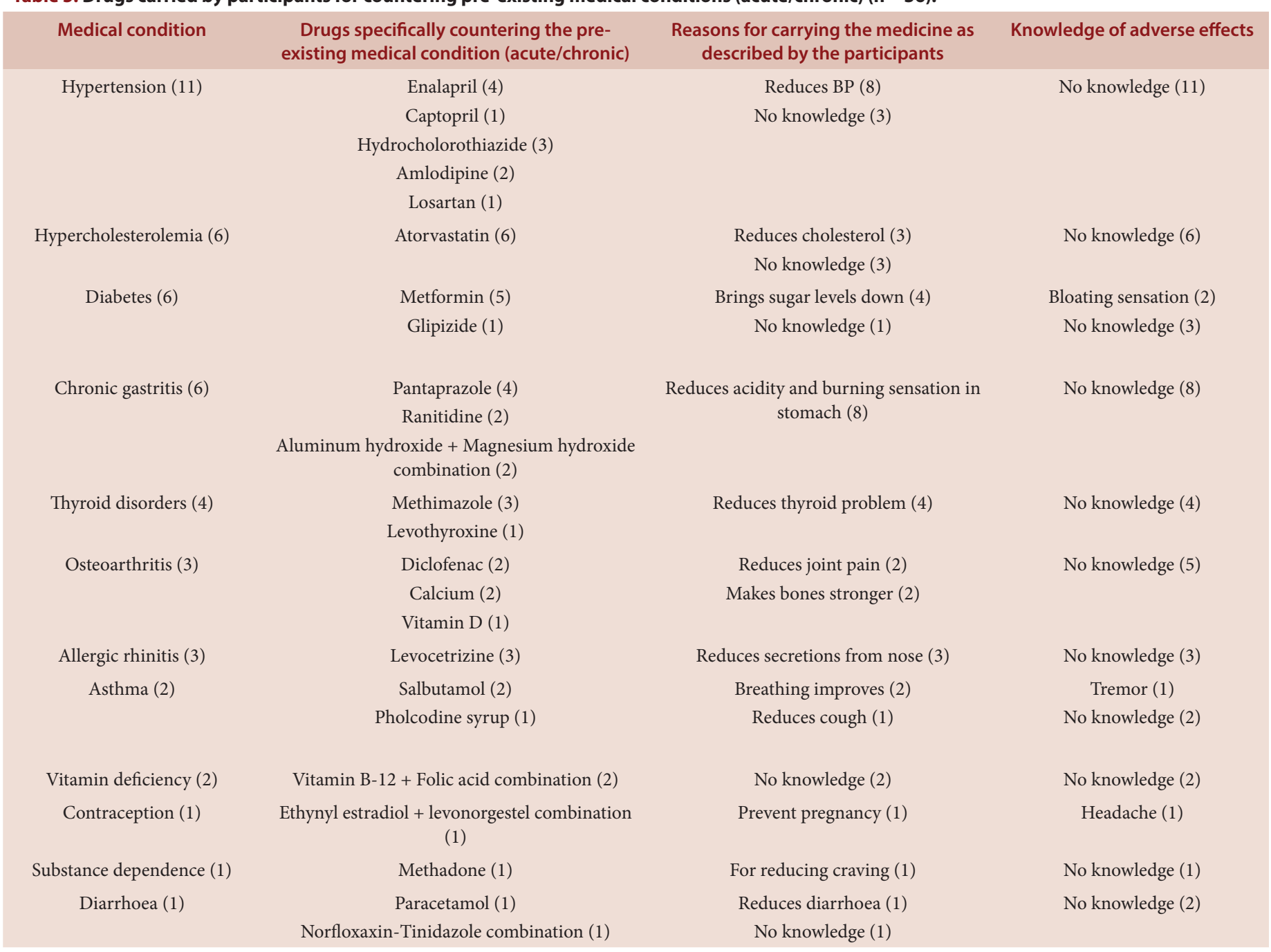

Some participants carried more than one medication or had more than one pre-existing ailment. 
Table 6: Drugs carried by participants with a pre-existing medical condition (chronic/acute) for countering anticipated travel-related medical problems during the journey $(n=17)$.

\begin{tabular}{|c|c|c|c|}
\hline Classification & Drugs & $\begin{array}{l}\text { Reasons for carrying the medicine, as described } \\
\text { by the participants }\end{array}$ & Knowledge of adverse events \\
\hline \multirow[t]{5}{*}{ NSAIDs } & Paracetamol (13) & Headache (2) & Rash (1) \\
\hline & Paracetamol + Ibuprofen combination (1) & Malaise (2) & No knowledge (15) \\
\hline & Aspirin (2) & Bodyache (7) & \\
\hline & & Fever $(2)$ & \\
\hline & & Wrong indication (2) & \\
\hline \multirow[t]{3}{*}{ Antacids } & Sodium bicarbonate sachet (1) & Acidity (1) & No knowledge (3) \\
\hline & Ranitidine (1) & Burning sensation in stomach (1) & \\
\hline & $\begin{array}{l}\text { Aluminium hydroxide and magnesium } \\
\text { hydroxide combination (1) }\end{array}$ & No knowledge (1) & \\
\hline \multirow[t]{2}{*}{ Herbal drugs } & Mentha piperata extract (Pudinhara) (1) & Bloating, gas (1) & No knowledge (2) \\
\hline & Neopeptine (1) & Indigestion (1) & \\
\hline
\end{tabular}

Values in parenthesis represent $\mathrm{n}$. Some participants carried more than one medication.

Table 7: Drugs carried by participants without any pre-existing medical conditions (chronic/acute) for countering anticipated travel-related medical problems during the journey $(n=34)$.

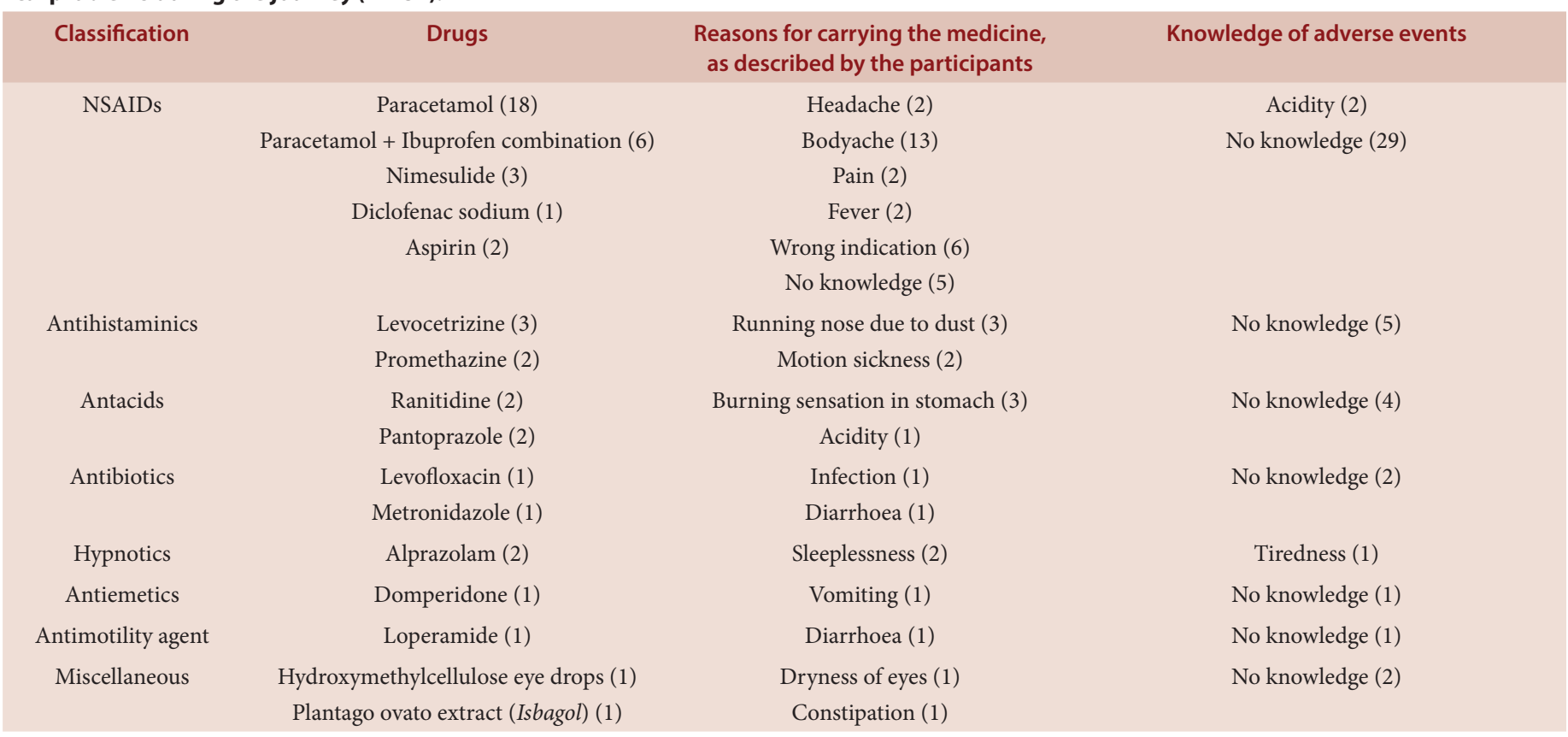

Values in parenthesis represent $\mathrm{n}$. Some participants carried more than one medication.

The majority of the respondents belonged to the stereotype of young males on a well-planned journey. The reason for the low number of female respondents could be due to the fact that in Indian Railways women prefer to travel in the coach reserved specifically for women rather than in mixed coaches, unless they are travelling with company. ${ }^{10}$ The reason for planning the journey in advance is scarcity of train tickets, if travel plans are spontaneous. ${ }^{11}$

Although a substantial number of respondents consumed medications or herbal products on a regular basis, carried medicines with them during long-distance journeys, consumed medicines with or without consultation with medical professionals, only a small percentage of them had adequate knowledge about the meaning of 'over-the-counter (OTC) drugs', branded/generic products, and the indications/adverse events of the drugs which they consumed. Also, a very small number of partici- pants carried medicines specifically to counter medical conditions that they might encounter while travelling, despite a substantial percentage of them claimed to have suffered from some form of a physical or psychological strain during their past long-distance travels. These findings indicate a need of initiatives to educate long-distance train travellers about the indications as well as the adverse effects of common OTC drugs such as NSAIDs, which may increase their preparedness. Since most respondents had little faith in pharmacies at railway stations, their quality may be improved so as to gain the trust of the passengers. Medical professionals must also spend more time with chronic patients so as to impart more information about the indications and the adverse effect of the prescribed drugs. ${ }^{12}$ This may lead to a cautious/well-informed consumption of drugs by the patients and an increase in the reporting rate of adverse drug events by patients to doctors. Overall, policies should be framed to 
Bhajoni and Meshram: Knowledge, attitude, and perceptions of Indian travellers

increase the knowledge of medicines in the masses, especially the more vulnerable groups like domestic travellers.

The common medical conditions that the passengers suffered from during their long-distance train travel were a wide range of mild negative symptoms such as malaise, cough, headache, tiredness, sleepiness, and exhaustion. This collection of symptoms, also called as 'travel-fatigue', is also common in travellers in other modes of transportation. ${ }^{6-13} \mathrm{Al}$ though, a majority of the participants actively sought help in case they encountered a medical problem while travelling, a substantial number did not want to do anything about it till their journey ended. This indicated that knowledge about the healthcare facilities provided by the Indian Railways and the drugs used to treat minor health problems encountered by travellers while travelling is sparse; hence, policy makers must take steps to generate more awareness about these two issues.

The Indian Railways provides a 'First Aid Box', containing essential medicines and dressing material, to the guard or train ticket collector to counter medical emergencies during the journey. Also, a helpline number ' 138 ' can be utilized by passengers to report their medical emergency while travelling. The station masters of each railway station have information about the doctors and hospitals in the vicinity, the facilities of which can be availed in case of a medical emergency. ${ }^{14}$

There is an increasing trend amongst Indian travellers in long-distance trains to use bottled water over home brought water as the quantity of the home brought water may be insufficient to last the entire journey and as most passengers do not prefer to refill their water bottles from the taps present at railway stations due to a risk of water-borne infections. ${ }^{15,16}$ The age-old practise in India of drinking water by the cup of the hand is dwindling away with time, as observed in our study.

Similarly, since the majority of the passengers preferred pantry-food and a substantial number also complained of being ill after consuming pantry-food, the hygiene and cleanliness of the pantry should be adequately addressed by the Indian Railways. Also, due to the inconvenience of carrying their own utensils from home in the journey, a majority of the respondents seemed to prefer pantry-food. ${ }^{17}$

As majority of the passengers used their right hand for washing/wiping their rectum after passing stools, for opening/closing water taps after using the toilet, and also for eating their food, water taps present in toilets of railway coaches could be a potential source for the spread of enteric infections. ${ }^{18}$ Hence, an adequate quantity of soap and hand sanitizer is needed in the toilets of railway coaches along with regular cleaning of the toilets at regular intervals to counter this risk.

The study had numerous limitations. First, the participants recruited in the study were few in number. Also, the study was conducted in the North-East division of the Indian Railways and included only participants who understood the English language leading to a selection bias. Hence, the inferences made in the study may have a questionable generalizability and may not represent the entire population. Second, the questionnaire designed was lengthy; hence, a substantial number of participants could not successfully complete the questionnaire. Third, although hand wash is an important component of personal hygiene while travelling, this issue was not addressed in a more direct fashion in the questionnaire. Information about the technique/timing of hand wash and whether the passengers carried hand sanitizers was not enquired. Fourth, although an association was found between the type of coach and some of the variables evaluated in the questionnaire, due to the low sample size the generalizability of this observation is questionable. However, despite these inadequacies of the study the data generated from the study is of great value as travel medicine is sparsely explored in India and data about the knowledge, perception, and attitude of the Indian population towards medicinal drugs, healthcare and hygiene while travelling in long-distance trains is absent, to the best of our knowledge. Future research targeting Indian travellers is necessary as the behavioural pattern portrayed by them may be different than those of Western travellers.

\section{CONCLUSION}

It was found that the knowledge about drugs in travellers in long-distance trains was not adequate. Hence, information about common OTC drugs needs to be delivered to the masses so as to increase their preparedness before a journey. Also, since most of the respondents had little knowledge about the healthcare facilities provided by the Indian Railways, steps need to be taken so as to create awareness about the same. Inculcating practises of improving hygiene and cleanliness while travelling will reduce the chances of acquiring infections during long-distance train travels.

\section{ACKNOWLEDGEMENT}

The authors are thankful to Dr. (Prof.) A.K. Gadpayle, Medical Superintendent and Director of PGIMER and Dr. RML Hospital, New Delhi for his constant support during the study. Dr. C.D. Tripathi, Director-Professor and Head of Department (Pharmacology), VMMC and Safdarjung Hospital is also acknowledged for his precious inputs.

\section{CONFLICT OF INTEREST}

None to be declared

\section{REFERENCES}

1. Ministry of Railways, Government of India. About Indian Railways [Internet] [cited 2016 August 24]. Available from: http://www.indianrailways.gov.in/railwayboard/.

2. Ministry of Railways. Statistical summary-Indian Railways [Internet]. [cited 2016 August 24]. Available from: http://www.indianrailways.gov.in/railwayboard/uploads/directorate/stat_econ/2014-15/Summary\%20Sheet_Eng.pdf.

3. Ministry of Railways, Government of India. Indian Railways: Facts and figures for 2014-15 [Internet]. [cited 2016 August 24]. Available from: http://www.indianrailways.gov.in/railwayboard/uploads/directorate/stat_econ/2014-15/Facts_Figure_2014-15_Eng.pdf.

4. Furuya $H$. Risk of transmission of airborne infection during train commute based on mathematical model. Environ Health Prev Med. 2007:12(2):78-83. https://doi.org/10.1007/BF02898153; PMid:21431823 PMCid:PMC2723643.

5. Mangili A, Gendreau MA. Transmission of infectious diseases during commercial air travel. Lancet. 2005;365(9463):989-96. https://doi.org/10.1016/S01406736(05)71089-8.

6. Waterhouse J, Reilly T, Edwards B. The stress of travel. J Sports Sci. 2004;22(10):946-65. https://doi.org/10.1080/02640410400000264 PMid:15768727.

7. Kelman CW, Kortt MA, Becker NG, Li Z, Mathews JD, Guest CS, et al. Deep vein thrombosis and air travel: record linkage study. BMJ. 2003;327(7423):1072. https://doi.org/10.1136/bmj.327.7423.1072 PMCid:PMC261739

8. Izadi M, Alemzadeh-Ansari MJ, Kazemisaleh D Moshkani-Farahani M. Air travel considerations for patients with heart failure. Iran Red Crescent Med J. 2014;16(6):e17213. https://doi.org/10.5812/ircmj.17213； PMid:25068047 PMCid:PMC4102980.

9. Gautret P, Gaudart J, Leder K, Schwartz E, Castelli F, Lim PL, et al. Travel-associated illness in older adults (>60 y). J Travel Med. 2012;19(3):169-77. https://doi. org/10.1111/j.1708-8305.2012.00613.x ; PMid:22530824

10. Hottola P. Touristic encounters with the exotic West: Blondes on the screens and streets of India. Tourism Recreational Research. 2002;27(1):83-87. https:// doi.org/10.1080/02508281.2002.11081359

11. Sharma AK, Manimala MJ. Sustainability of the Indian Railways turnaround: stage theory perspective, 2008. IIM Bangalore Research Paper No. 226 [Internet]. [cited 2016 August 24]. Available from: http://ssrn.com/abstract=2144044.

12. Hughes L, Whittlesea C, Luscombe D. Patient's knowledge and perceptions of the side-effects of OTC medication. J Clin Pharm Therapeutics. 2002;27(4):2438. https://doi.org/10.1046/j.1365-2710.2002.00416.x.

13. Herxheimer A. The prevention and treatment of jet lag. BMJ. 2003;326(7384):296-7. https://doi.org/10.1136/bmj.326.7384.296 PMid:12574022 PMCid:PMC1125170.

14. Ministry of Railways, Government of India. Indian Railways medical manual. 3rd ed. New Delhi: Publications division, GOl; 2000

15. Steffen R, Tornieporth N, Clemens SC, Chatterjee S, Cavalcanti A, Collard F, 
et al. Epidemiology of travellers-diarrhea: details of a global survey. Journal of Travel Medicine. 2004;11(4):231-8. https://doi.org/10.2310/7060.2004.19007 ; PMid:15541226.

16. Walsh TR, Weeks J, Livermore DM, Toleman MA. Dissemination of NDM-1 positive bacteria in the New Delhi environment and its implications for human health: an environment point prevalence study. The Lancet Infectious Diseases.
2011;11(5):355-62. https://doi.org/10.1016/S1473-3099(11)70059-7.

17. Ghimere $\mathrm{KB}$, editor. The native tourist: mass tourism within developing countries. Oxfordshire: Earthscan publications; 2001.

18. Mendes MP, Lynch DJ. A bacteriological survey of washrooms and toilets. Journal of Hygiene. 1976;76(2):183-90. https://doi.org/10.1017/S002217240005508X.

Cite this article : Bhajoni PS, Meshram GG. Knowledge, attitude, and perceptions of Indian long-distance train travellers towards medicinal drugs, healthcare, and hygiene while travelling: A questionnaire-based survey. Int J Med. Public Health. 2017; 7(2):83-91. 